\title{
Heterogeneity in the Association Between Prediabetes Categories and Development of Impaired Renal Function in A 5-Year Follow-Up
}

\section{Marjan Manouchehri}

Department of Public Health and Maternal and Child Health, Faculty of Medicine, Universidad Complutense de Madrid, Madrid, Spain

\section{Lucía Cea-Soriano ( $\nabla$ tlcea@ucm.es )}

Department of Public Health and Maternal and Child Health, Faculty of Medicine, Universidad Complutense de Madrid, Madrid, Spain

\section{Josep Franch-Nadal}

Barcelona City Research Support Unit / University Institute for Research in Primary Care Jordi Gol, Barcelona, Spain

Antonio Ruiz

Centro de Salud Universitario Pinto, Madrid, Spain

\section{Albert Goday}

Servicio de Endocrinología, Hospital del Mar, IMIM, Barcelona, Spain

\section{Rosa Villanueva}

Department of Public Health and Maternal and Child Health, Faculty of Medicine, Universidad Complutense de Madrid, Madrid, Spain

\section{Javier Diez-Espino}

Tafalla Health Center, Navarra, Spain

\section{Manel Mata-Cases}

La Mina Primary Care Center, Barcelona, Spain

\section{Carolina Girladez-García}

Servicio de Medicina Preventiva, Hospital Universitario del Tajo, Aranjuez (Madrid).

\section{Enrique Regidor}

Department of Public Health and Maternal and Child Health, Faculty of Medicine, Universidad Complutense de Madrid, Madrid, Spain

\section{Research Article}

Keywords: IRF, diabetes, patients, hyperfiltration

Posted Date: December 2nd, 2020 
DOl: https://doi.org/10.21203/rs.3.rs-110114/v1

License: (c) (1) This work is licensed under a Creative Commons Attribution 4.0 International License. Read Full License 


\section{Abstract}

Background: Impaired renal function (IRF) in patients with diabetes impose a significant health burden. This study evaluates the association of three diagnostic categories of with a reduction on glomerular filtration rate

Methods: We used data from PREDAPS prospective study a cohort of 1072 subjects with prediabetes and another cohort of 772 subjects without prediabetes were follow-up from 2012 to 2017. Prediabetes was defined according to American Association of Diabetes (ADA) criteria. IRF was defined as having a glomerular filtration rate $<60 \mathrm{~mL} / \mathrm{min} / 1.73 \mathrm{~m} 2$. Incidence rate of IRF according to prediabetes and diagnostic categories of prediabetes as well as Kaplan Meir figures were calculated. Hazard ratios (HR) for the association of the prediabetes diagnostic categories of prediabetes with IRF, adjusting for potential confounders, were estimated by Cox regression models.

Results: IRF Incidence rate per 100 person-years in subjects without prediabetes was 1.72 (95\% confidence interval [Cl]: 1.34-2.21) and $1.79(95 \% \mathrm{Cl}: 1.45-2.20)$ for those with prediabetes stage, log rank test $p=0.84$. Prediabetes was associated with an adjusted HR of IRF onset of 0.76 (95\% Cl: 0. 54-1.07). Corresponding HR for diagnostic categories were 0.68 (95\% Cl:0.40-1.15) for those with both altered parameters, 0.68 (95\% Cl: 00.40-1.15) for those with only impaired $\mathrm{HbA} 1 \mathrm{c}$ and 1.12 (95\% Cl: $0.68-1.85)$ for those with only impaired FPG.

Conclusions: The present study reflects an overall trend towards a slightly decreased risk of IRF onset associated to prediabetes except for individuals with only isolated impaired FPG. Further studies are warranted to fully assess the renal progression of each group.

\section{Introduction}

Approximately 422 million people globally suffer from diabetes globally and 1.6 million deaths are directly attributed to this each year. [1-2] Type 2 diabetes (T2D) is the most common, resulting as a result of increased insulin resistance.. Diabetes is among the leading causes of chronic kidney failure around the world. [2] Impaired renal function (IRF) in patients with diabetes impose a significant health burden.[3] Deterioration of the renal function in combination with diabetes can lead to poorer health prognosis. [4]

It has been reported that up to $40 \%$ of patients in early stage of T2D demonstrate some degree of microvascular complication.[5] In addition, a high proportion of patients with diabetes are found to have non-diabetic renal disease (NDRD), being nephroangiosclerosis (NAS) the most frequent cause [6-7] Metabolic changes associated with diabetes lead to glomerular hypertrophy, glomerulosclerosis, and tubulointerstitial inflammation and fibrosis. [5] In addition, according to various studies, one-third of adults with newly diagnosed diabetes mellitus already have kidney damage, suggesting that IRF may occur in pre-diabetic state. [8] The effect of hyperglycemia on the occurrence of IRF may start before glucose levels reaches diabetic ranges. Other diabetes-related microvascular complications, such as 
retinopathy and neuropathy have been described in some previous studies, in subjects with prediabetes. [9-10]

World Health Organization (WHO) has emphasized the early detection of IRF as an important component of its strategies for prevention of noncommunicable diseases. [10] However, the long-term influences of prediabetes on kidney function remains unknown. In order to fill major gaps in the role of prediabetes on IRF onset, the aim of this study was to evaluate the association between prediabetes and three diagnostic categories of prediabetes and incidence rate of IRF using a prospective cohort of individuals with prediabetes followed up by primary care physicians from Spain.

\section{Methods}

\section{Study design}

The Cohort Study in Primary Health Care on the Evolution of Patients with Prediabetes (PREDAPS), is a prospective study conducted by 125 Primary Care physicians at their practices from different provinces of Spain. The details of the cohort have been described elsewhere.[11-12] The age range of patients was between 30 and 74 years. The study period started in 2012 and continued up to the fifth annual follow-up visit in 2017. All individuals with the following criteria at baseline were excluded: diagnosis of diabetes, terminal disease, pregnancy, surgery, hospital admissions in the previous 3 months at study entry or any hematologic disease which could alter glycated hemoglobin A1c (HbA1c) values. The estimate glomerular filtration rate (eGFR) at baseline was calculated according to the Chronic Kidney Disease Epidemiology Collaboration (CKD-EPI) [9]. A total of 92 subjects did not have measures eGFR at baseline and an additional 66 patients had values below $60 \mathrm{~mL} / \mathrm{min} / 1.73 \mathrm{~m} 2 \mathrm{~min}$ which is already considered as a reduction; therefore, they were excluded due to this pre-existing condition. Final population included a total of 1844 subjects.

Study population was subdivided into two mutually exclusive cohorts according to glycemic parameters following American Diabetes Association (ADA) criteria: cohort of subjects with prediabetes $(n=1,072)$ and cohort of subjects without prediabetes $(\mathrm{N}=772)$. Prediabetic cohort was subdivided into three mutually exclusive diagnostic categories based on impaired glycemic parameters. First category, included all subjects with only impaired fasting plasma glucose (FPG range: $100-125 \mathrm{mg} / \mathrm{dL}$ [5.6-6.9 mmol/L]), second category included all subjects with isolated impaired $\mathrm{HbA1c}$ (HbA1c range: 5.7-6.4\% [39-47 $\mathrm{mmol} / \mathrm{mol}]$ ) and third category included subjects with both impaired glycemic parameters (FPG and $\mathrm{HbA1c)}[13]$

Study period started on 2012 up to the fifth follow-up visit. Once meeting the eligibility criteria, individuals were followed up from baseline until the occurrence of one of the following end points: i) IRF ii) death, iii) loss of follow up or iv) end of study period (2017), whichever came first. IRF occurrence was measured at each annual visit and considered when a subject presented an eGFR $<60 \mathrm{~mL} / \mathrm{min} / 1.73 \mathrm{~m} 2$ during the follow up. IRF patients were immediately censored within the follow up. 
Subjects gave their written informed consent for participation. The study was classified by the Spanish Agency of Medicines and Medical Devices as a Non-Interventional (Observational) Post-Authorization Study, and the study protocol was approved by the Parc de Salut Mar Clinical Research Ethics Committee in Barcelona (2011-4274-I).

\section{Assessment of covariables}

Data were collected at the first visit (baseline period). Information on biographical data, family history, comorbidities, demographical data (i.e. including social support and socio-economic position), lifestyle factors, and drug use were obtained from medical records of study subjects as well as a personal interview conducted by the physicians.

Comorbidities were categorized as follows. Hypertension (HTN) classified as systolic blood pressure $\geq 140 \mathrm{mmHg}$ and/or diastolic blood pressure $\geq 90 \mathrm{mmHg}$, being treated by antihypertensive drugs or previous diagnosis of HTN. Hypercholesterolemia, as serum total cholesterol $\geq 250 \mathrm{mg} / \mathrm{dL}, \mathrm{HDL}-\mathrm{C}$ as $<40$ $\mathrm{mg} / \mathrm{dL}$ in men or $<50 \mathrm{mg} / \mathrm{dL}$ in women, and hypertriglyceridemia (HTG) as serum triglycerides $\geq 200$ $\mathrm{mg} / \mathrm{dL}$.

Lifestyle factors were categorized as follows: Body mass index (BMI) between 25.0 and $29.9 \mathrm{~kg} / \mathrm{m}^{2}$ classified as overweight, general obesity defined as $\mathrm{BMI} \geq 30 \mathrm{~kg} / \mathrm{m}^{2}$; abdominal obesity defined as waist circumference $\geq 102 \mathrm{~cm}$ in men and $\geq 88 \mathrm{~cm}$ in women. Smoking categories into smokers, ex-smokers and non-smokers; Alcohol consumption as: daily drinkers, occasional drinkers, and non-drinkers (never or former) which included ex-drinkers and teetotalers. Physical activity was classified according to World Health Organization (WHO) recommendations. Subjects followed the recommendations if they practiced more than 150 minutes per week of moderate aerobic physical activity, more than 75 minutes each week of vigorous aerobic physical activity or an equivalent combination.[14] For the adherence to Mediterranean diet (MedDiet), it was used as reference the definition followed in ATTICA study and their designed Panagiotakos score.[15] For each twenty types of studied nutrients, subjects responded the frequency of consumption: every day, more than three times a week, two times each week, once a week, less than once a week, never or rarely. Zero as a score in each meal was considered if the subject was having a less healthy diet and 4 was considered if the subject was having a very healthy diet.

\section{Statistical analysis}

First of all, a descriptive analysis was conducted showing the distribution of the baseline characteristics among those who were classified in prediabetic cohort and those in the cohort without prediabetes. Continuous and count variables were described using mean ( \pm standard deviation [SD]), median (quartiles) and $95 \%$ confidence intervals $(95 \% \mathrm{Cl})$. Incidence rate of IRF per 100 person-years together with $95 \% \mathrm{Cl}$ were calculated in each cohort. Incidence rate of IRF according to prediabetes categories was also calculated. Kaplan Meier survival functions with log rank test were performed to compare the survival distributions across each group. Cox proportional hazards analyses were used to estimate the hazard ratios (HR) with $95 \% \mathrm{Cl}$ for the association of covariables with incidence rate of IRF and for the 
association of prediabetes and diagnostic categories of prediabetes with reduction of incidence rate of IRF. Results of the association of prediabetes and diagnostic categories of prediabetes with incidence rate of IRF onset were shown for four levels of adjustment: model 1 (adjusted by age and sex), model 2 (model 1 plus adjusted by lifestyle variables such as smoking status, regular physical activity, high-risk alcohol consumption, adherence to MedDiet score, model 3 (model 2 plus adjusted by metabolic risk factors such as waist circumference, BMI, hypertension (HTN), total cholesterol, low HDL-cholesterol, triglycerides), and model 4 (model 3 plus adjusted by use of angiotensin converting enzyme inhibitors [ACEIs] or angiotensin II receptor blockers [ARBs]).). Statistical analyses were performed using the STATA package version 12.0 (StataCorp LP, College Station, TX, USA).

\section{Results}

\section{Baseline characteristics}

A total of 1,844 patients ( $95 \%$ Spanish origin) were included in the present study, from whom 1,072 (58.1\%) had prediabetes according to the ADA guidelines the mean age of prediabetic and normoglycemic groups were 59.1 (SD 9.3) and 56.6 (SD 10.3) years, respectively. At baseline, lifestyle factors were similarly distributed among patients with prediabetes compared with normoglycemia group. In terms of comorbidities, more than half of patients with prediabetes presented metabolic syndrome compared with $12.4 \%$ in the normoglycemic group. Likewise, the prevalence of HTN was higher in the prediabetic group. In particular, $36.9 \%$ of patients with prediabetes had treatment with ACEls or ARBs drugs versus $23.6 \%$ in the normoglycemia group. For all metabolic parameters measured, prediabetic group presented a higher mean ( $p$ value $<0.01$ ) with the exception of total cholesterol which the distribution was almost the same $(210 \mathrm{mg} / \mathrm{dL})$. Finally, the mean value of eGFR $(\mathrm{mL} / \mathrm{min} / 1.73 \mathrm{~m} 2)$ was very similar across groups: 89.1 (SD:13.7) for prediabetic cohort and 90.4 (SD:13.4) for normoglycemic cohort. (Table 1)

\section{Incidence rate of IRF overall and by prediabetes categories}

A total of 88 incident cases of IRF occurred in the prediabetic group and 61 cases occurred in the normoglycemic group. Incidence rates of IRF among the two study groups, overall and by prediabetes categories, are shown in Table 2. The overall incidence rate of IRF per 100 person-years was 1.72 ( $95 \% \mathrm{Cl}$ : 1.34-2.21) and $1.79(95 \% \mathrm{Cl}: 1.45-2.20)$, log rank test $\mathrm{p}=0.84$. Focusing on the prediabetic group, the incidence of IRF was lower in the HbA1c 5.7- $6.4 \%$ group (IR: 1.40 [95\% Cl: 0.89-2.19]) and highest among those with isolated FPG $100-125 \mathrm{mg} / \mathrm{dL}$ (IR: 2.06 [95\%Cl: 1.36-3.13]) log rank test $\mathrm{p}=0.74$. Figure 1 shows the Kaplan Meier survival function of IRF by type of cohort and Figure 2 by prediabetes categories.

\section{Covariables and incidence rate of IRF}

Table 3 shows the risk factors associated to IRF onset sex- and age-adjusted. There was a trend towards and increase risk of IRF according to age, for example those aged 50 to 64 years had a HR of 5,11 (95\%Cl: $1.85-14.12)$ and 16.48 (95\% Cl: 6.06-44.85) for those aged $\geq 65$ years. Adherence to MedDiet 
showed a protective effect against reduction of eGFR (HR: 0.75 (95\% Cl: 0.54-1.04). On the contrary, metabolic conditions such as waist circumference $\geq 102 \mathrm{~cm}$ in men and $\geq 88 \mathrm{~cm}$ in women or having a $\mathrm{BMI} \geq 30$ were associated with an increased risk of reduction of eGFR (HR: 1.39 [95\%Cl: 0.54-1.04] and 1.21 [95\% Cl: 0.87-1.68], respectively). History of HTN showed a HR of 2.08 (95\%Cl: 1.38-3.12) and 1.82 (95\% Cl: 1.31-2.52) for use of ACEls/ARBs but there was not association with metabolic syndrome (1.14 [95\% Cl: 0.82-1.59]). Having levels of $\mathrm{HDL}$-cholesterol $(\mathrm{mg} / \mathrm{dL})$ as $<40 \mathrm{mg} / \mathrm{dL}$ in $\mathrm{men}$ or $<50 \mathrm{mg} / \mathrm{dL}$ was associated with a HR of IRF of $1.28(95 \% \mathrm{Cl}: 0.86-1.91)$.

\section{Association of prediabetes and diagnostic categories of prediabetes with incidence rate of IRF}

Results are shown in Table 4. Using the cohort of subjects without prediabetes as reference, prediabetes was associated with a HR of IRF onset of $0.89(95 \% \mathrm{Cl}$ : 0.64-1.24) when adjusting by age and sex. This estimate remained the same when adding lifestyle variables to the model and HR decreased to 0.76 (95\% Cl: 0.54-1.07) when adding metabolic conditions together with lifestyle factors. Of note, the estimate remained constant when adding on top of this model use of ACEls or ARBs (Table 4). When evaluating the risk of IRF onset according to prediabetes diagnostic categories, a trend towards a decreased risk of IRF onset was observed in subjects with both parameters altered (FPG and HbA1c) and those with only impaired HbA1c levels, corresponding HR estimates were 0.68 (95\% $\mathrm{Cl}: 0.40-1.15)$ and 0.68 (95\% Cl: 0.401.15), respectively. However, subjects with only impaired FPG did not show any association (HR: 1.12 [95\% Cl: 0.68-1.85]).

\section{Discussion}

Findings of this prospective cohort study reflect an overall trend towards a slightly decreased risk of IRF onset associated to prediabetes with an adjusted HR of 0.76 . This finding is restricted to subjects who only had impaired $\mathrm{HbA} 1 \mathrm{c}$ and those who had both parameters impaired: both groups represent $80 \%$ of the subjects with prediabetes and their adjusted HR was 0.76 . Instead, subjects with only impaired FPG levels had a slightly increased risk (adjusted HR=1.12).

A recent meta-analysis, including a total of eight cohort studies with subjects with impaired FPG as prediabetes criteria, has also reported a modest increased risk of IRF associated to impaired FPG [16]. It is known that hyperglycemia increases the production of reactive oxygen species, which lead to the accumulation of advanced glycation end products. This, in turn, activate intracellular signaling pathways such as protein kinase $C$ and intensify the effects of the renin-angiotensin system.[5] This effect may lead to early onset of glomerular hyperfiltration and subsequently a decreased of IRF onset. In addition, eGFR has been reported to decrease faster in patients with hyperfiltration which might lead to kidney damage occurrence. [17-18] Although there is still controversy towards if hyperfiltration occurs in the early stages of hyperglycemia, several studies have found significant associations between hyperfiltration and prediabetes.[19,20] Specifically, it has been suggested how the prevalence of hyperfiltration increases with worsening stages of prediabetes. [19]. 
The reduced risk of IRF was concentrated among subjects who only had impaired $\mathrm{HbA} 1 \mathrm{c}$ and those who had both parameters, while subjects with isolated impaired FPG showed a slightly increased risk of IRF, suggesting that these subjects might still preserve the renal function, and this is not via hyperfiltration. These results are consistent with a prior study using the same study population where it was found how individuals with impaired of both FPG and HbA1c had an OR of hyperfiltration of 1.69 (95\% Cl: $1.05-$ 2.74) while there was no association among individuals with solely impaired FPG levels [22].

World Health Organization (WHO) has emphasized the early detection of IRF as an important component of its strategies for prevention of noncommunicable diseases, [10] as this has proven to improve outcomes for both individual and national healthcare economy. Since hyperfiltration is thought to be an early and proxy to reversible stage of kidney damage [21] monitoring and identifying high risk prediabetic patients might result as an effective and cost-efficient preventive strategy. For example, both FPG and $\mathrm{HbA1C}$ levels can serve as chemical marker to identify early deterioration of IRF and avoid nephropathy. Another advantage of intensive blood glucose control in the prediabetic state can be seen in the long-term protective effect known as metabolic memory.[13] Thus, early intensive glycemic control could prevent irreversible damage that has been associated with hyperglycemia through closer monitoring of patients. [22] A 24\% reduction in microvascular complications, including IRF, compared with tight glycemic control has been found in another study that followed up subjects with T2D for up to ten years. [23] Intensive glycemic control resulted in a $33 \%$ reduction in the risk of microproteinuria, proteinuria. Also a significant reduction in the proportion of patients with a doubling of the blood creatinine level $(0.9 \%$ versus $3.5 \%)$ relative to the conventional therapy group was oberved. [23]

Findings of the present study show that baseline risk factors such as (e.g. age, sex, ethnicity, and family history) and other factors (e.g., acute kidney injury, HTN, dietary factors, and obesity) can lead to diabetes kidney disease. [16] Hypertension is the leading cause of Impaired renal function. [19, 21,23] Observational studies have indicated that blood pressure increases with age, adding to the long-term population burden of IRF. According he Kidney Early Evaluation Program (KEEP) and NHANES project, there is an increase in the prevalence and severity of IRF with increasing of age, as expected. [24] Also, abdominal obesity, measured as waist circumference, show an increased risk of IRF, although did not reach statistical significance. Regarding nutritional therapy in IRF patients is still under debate. Although nutritional therapy was implemented to reduce amount of high biological value proteins, currently the interest is also focus on the possibility of delaying IRF progression. $[17,25]$ The current study found a protective effect against IRF onset associated with high adherence to the MedDiet, characterized by high consumption of extra-virgin olive oil, nuts, red wine, vegetables and polyphenol-rich elements (HR: 0.75 [95\% Cl: 0.54-1.04]).

This study reflects that it is possible to carry out a prospective study, with data obtained at the national level by primary care physicians during clinical practice. However, analytical determinations were made in different laboratories, which could have led to some misclassification. Given that each subject was assigned to the same laboratory during follow-up, this limitation should be non-differential in relation to 
the result, since an association between the methods used by specific laboratories and the development of IRF is unlikely.

This study used the IRF-EPI creatinine-based equation. This equation is more accurate and has less bias than the commonly used Diet Modification in Kidney Disease (MDRD) equation, especially at higher GFR levels. $[9,26]$ In addition, GFR was estimated rather than using the gold standard of insulin clearance for this measure. Insulin clearance is more accurate than eGFR, but it is not cost-effective and it is an invasive method that is not used in clinical practice in Primary Care on a daily basis. However, it should be noted that eGFR was calculated from a single serum creatinine measurement. However, this classification is unlikely to be differential with respect to prediabetes status.

Finally, researchers were unable to determine a time-dependent variable. However, the vast majority of the factors considered in the present study are chronic conditions or long-term lifestyle factors not susceptible to a fast variation within the follow-up during the study period.

Prediabetes is a temporary stage from normal glucose tolerance to diabetes which can be associated with long term macro or micro vascular complications. The present study did not show an increased risk of IRF onset associated to prediabetes, with the exception of those with isolated impaired FPG. Further study is warranted to test the effect of these risk factors on the various prediabetic state in the multinational large cohort on the reduction of IRF onset.

\section{Abbreviations}

ACEls - Angiotensin converting enzyme inhibitors

ARBs - Angiotensin II receptor blockers

ADA - American Diabetes Association

BMI - Body mass index

IRF - Impaired renal function

$\mathrm{Cr}$ - Creatinine

DBP - Diastolic blood pressure

FPG - Fasting plasma glucose

GFR - Glomerular filtration rate

HbA1c - Glycated hemoglobin A1c

HDL - High-density lipoprotein 
MedDiet- Mediterranean Diet

NS - Not significant

OGTT - Oral glucose tolerance test

SD - Standard deviation

SBP - Systolic blood pressure

T2DM - Type 2 diabetes

WC - Waist circumference

\section{Declarations}

Ethics approval and consent to participate: The study was classified by the Spanish Drug and Health Product Agency as a Non-Interventional (Observational) Post-Authorization Study, and the protocol was approved by the Parc de Salut Mar Clinical Research Ethics Committee in Barcelona. Informed consent was obtained from all participants and/or their legal guardians

Method and Declaration section: Authors confirm that all methods were performed in accordance with the relevant guidelines and regulations.

Consent for publication: Non-applied

Availability of data and materials. The datasets used and/or analyzed during the current study available from the corresponding author on reasonable request. Competing interests None declared

Funding. This research did not receive any specific grant from funding agencies in the public, commercial, or not-for-profit sectors.

Authors' contributions: MM, LCS and ER analyzed and interpreted the data. LCS, ER and JFN wrote the outline and edited the manuscript. AR, AG, RV, JD-E , MM-C and CG-G- reviewed/edited the manuscript and contributed to discussion. As reviewed and edited the manuscript. All authors read and approved the final manuscript

Guarantor's: Dr. Regidor is the guarantor of this work and, as such, had full access to all the data in the study and takes responsibility for the integrity of the data and the accuracy of the data analysis.

Conflict of interest: none declared.

Acknowledgements:

The other members of the PREDAPS Study Group are: 
Margarita Alonso (CS De la Eria, Asturias), Beatriz Álvarez (CS Andrés Mellado, Madrid), Fernando Álvarez (CS La Calzada 2 , Asturias), J Carlos Álvarez (CS Eras de Renueva, León), Mª del Mar Álvarez (CS Hereza, Madrid), J Joaquín Antón (CS Murcia-Centro, Murcia), Oriol Armengol (EAP Poblenou, Barcelona), Sara Artola (CS José Marvá, Madrid), Luis Ávila (Consultorio Almachar, Málaga), Carmen Babace (CS Rodríguez Paterna, La Rioja), Lourdes Barutell (CS Andrés Mellado, Madrid), Ma Jesús Bedoya (CS Hereza, Madrid), Belén Benito (EAP Raval Sud, Barcelona), Beatriz Bilbeny (EAP Raval Sud, Barcelona), Marti Birules (EAP Poblenou , Barcelona), Concepción Blanco (CS Sada, A Coruña), Ma Isabel Bobé (EAP La Mina, Barcelona), Carmen Boente (CS Porriño, Pontevedra), Antonia Borras (CS Canal Salat, Baleares), Remei Bosch (EAP Girona 2 , Girona), Ma Jesús Brito (CS La Matanza, Baleares), Pilar Buil (EAP Azpilagaña, Navarra), J José Cabré (EAP Reus-1 , Tarragona), Ainoha Cambra (CS Arrabal, Zaragoza), Francisco Carbonell (CS Mislata, Valencia), Francisco Carramiñana (CS San Roque, Badajoz), Lourdes Carrillo (CS La Victoria de Acentejo, Santa Cruz de Tenerife), Ana Casorrán (CS Fuente de San Luis, Valencia), Rafael Colas (CS Santoña, Cantabria), Blanca Cordero (CS Sta. María de Benquerencia, Toledo), Xavier Cos (EAP Sant Martí de Provençals, Barcelona), Gabriel Cuatrecasas (CAP de Sarrià, Barcelona), Cristina De Castro (CS Sta. María de Benquerencia, Toledo), Manuel De la Flor (CS Ntra. Sra. de Gracia , Sevilla), Carlos De la Sen (Consultorio San Gabriel, Alicante), Rosa Mar De Miguel (EAP Pubillas Casas, Barcelona), A María De Santiago (Unidad Docente de Atención Familiar y Comunitaria, Guadalajara), Mercedes Del Castillo (CS Andrés Mellado, Madrid), Ma Carmen Durán (CS Lavadores Vigo, Pontevedra), Patxi Ezkurra (CS Zumaia, Guipúzcoa), Paula Gabriel (EAP Badia del Vallès , Barcelona), Javier Gamarra (CS Medina del Campo Rural, Valladolid), Francisco García (CS Don Benito Este, Badajoz), Luis García-Giralda (CS Murcia Centro, Murcia), F Javier García-Soidán (CS Porriño, Pontevedra), Ma Teresa Gijón (CS Los Yébenes, Madrid), Albert Goday (Endocrinología Hospital del Mar, Barcelona), Ángel Gómez (CS Lasarte, Guipúzcoa), María del Carmen Gómez (CS Vélez-Málaga Norte, Málaga), J Carles González (Girona 3, Girona), María González (CS Alcantarilla Sangonera, Murcia), Esteban Granero (CS Vista Alegre Murcia , Murcia), Ángela Trinidad Gutiérrez (CS El Calero, Las Palmas), Félix Gutiérrez (CS Bombarda-Monsalud, Zaragoza), Luisa Gutiérrez (CS Beraun, Guipúzcoa), M Ángel Gutiérrez (CS Ávila Sur Oeste, Ávila), Ana Ma Hernández (CS El Calero, Las Palmas ), Mercedes Ibáñez (CS Vandel, Madrid), Rosario Iglesias (CS Lain Entralgo, Madrid), Dimas Igual (CS Manuel Encinas, Cáceres), Jaime Innenaraty (CS Hereza Leganes, Madrid), Jaime Iriarte (CS Aizarnazabal-Getaria, Guipúzcua), Ángeles Jurado (CS Salvador Caballero, Granada), Rafael Llanes (Villanueva de la Cañada, Madrid), Flora López (EAP Martorell , Barcelona), Regina López (EAP El Carmel, Barcelona), Riánsares López (CS Artilleros, Madrid), Ángela Lorenzo (CS Alcalá de Guadaira, Madrid), Carmen Losada (UGC Adoratrices, Huelva), Ramón Macía (CS Roces Montevil, Asturias), Fernando Malo (CS Ares, A Coruña), José Mancera (CS Ciudad Jardín, Málaga), Ma José Mansilla (CS Martín de Vargas, Madrid), Ma Teresa Marín (CS General Ricardos, Madrid), José Luis Martín (CS Salvador Caballero, Granada), F Javier Martínez (CS Federica Monseny, Madrid), Juan Martínez (CS Yecla, Murcia), Ma del Carmen Martínez (EAP Raval Sud, Barcelona), Rosario Martínez (CS Oñati, Guipúzcoa), Anna Massana (EAP Raval Sud), Ma Soledad Mayayo (CS Martín de Vargas, Madrid), J Javier Mediavilla (CS Burgos Rural, Burgos), Luis Mendo (CS Cadreita, Navarra), J Manuel Millaruelo (CS Torrero La Paz, Zaragoza), Alicia Monzón (CS Vecindario, Las Palmas ), Ana Moreno (CAP San Roque, Badajoz), Pedro Muñoz (Unidad Docente de Medicina Familiar y 
Comunitaria, Cantabria), Xavier Mundet (EAP Carmel, Barcelona), Teresa Mur ( CAP Terrasa Sud, Barcelona), Emma Navarro (CS Añaza, Santa Cruz de Tenerife), Jorge Navarro (CS Salvador Pau, Valencia), Pedro Nogales (CS Las Águilas, Madrid), J Carlos Obaya (CS Chopera, Madrid), Cristina Oria (CS Aizarnazabal-Guetaria, Guipúzcoa), Francisco Javier Ortega (CS Campos-Lampreana, Zamora), Francisca Paniagua (CS Ciudad Jardín, Málaga), José Luis Pardo (CS Orihuela I, Alicante), Francisco Carlos Pérez (CS Martín de Vargas, Madrid), Pedro P Pérez (CS Mallen, Sevilla), Neus Piulats (EAP Raval Sud , Barcelona), Raquel Plana (CS Ponteareas, Pontevedra), Nuria Porta (CAP Terrassa Sud , Barcelona), Santiago Poveda (CS Jumilla, Murcia), Luis Prieto (CS Cáceres-La Mejostilla, Cáceres), Ramón Pujol (EAP Tremp, Lleida), Sol Reixa (CS Arrabal, Zaragoza), Jazmín Ripoll (CS Fuente de San Luis, Valencia), Antonio Rodríguez (EAP Anglès, Girona), J José Rodríguez (CS Villaviciosa de Odón, Madrid), Ma Angeles Rollán (CS Los Yébenes, Madrid), Ma Teresa Rollán (CS Hereza, Madrid), Laura Romera (EAP Raval Nord, Barcelona), Pilar Roura (EAP Badia de Vallès, Barcelona), Jóse Félix Rubio (CS Lasarte, Guipúzcua), Irene Ruiz (EAP La Torrassa, Barcelona), Manuel Antonio Ruiz (CS Agost, Alicante), Isabel Sáenz (CS Espronceda, Madrid), Julio Sagredo (CS Los Rosales, Madrid), Alejandro Salanova (CS Fuente de San Luis, Valencia), L Gabriel Sánchez (CS Carballeda, Zamora), Manuel Sánchez (CS Vista Alegre Murcia, Murcia), Gloria Sanz (CS San José centro, Zaragoza), Mateu Seguí (UBS Es Castell, Baleares), Josefina Servent (EAP El Carmel, Barcelona), Dulce Suárez (CS El Calero, Las Palmas ), Eduard Tarragó (EAP Bellvitge, Barcelona), Jesús Torrecilla (CS Bombarda-Monsalud, Zaragoza), José Luis Torres (CS Rodríguez Paterna, La Rioja), Merè Villaró (CAP Terrassa sud, Barcelona), Carmen Yuste (EAP Badia del Vallès, Barcelona).

\section{References}

1. World Health Organization. Use of glycated haemoglobin (HbA1c) in the diagnosis of diabetes mellitus.[cited Oct 20]. Available from:https://www.who.int/diabetes/publications/diagnosis_diabetes2011/en/.

2. Global report on diabetes. [cited Oct 20]. Available from:https://www.who.int/diabetes/globalreport/en/

3. Gorostidi M, Sánchez-Martínez M, Ruilope LM, et al. Chronic kidney disease in Spain: Prevalence and impact of accumulation of cardiovascular risk factors. Nefrologia 2018;38:606-615.

4. Razeghi E, Heydarian P, Heydari M. The frequency of prediabetes and contributing factors in patients with chronic kidney disease. Rev Diabet Stud. 2011;8(2):276-281. [5]

5. Alicic RZ, Rooney MT, Tuttle KR. Diabetic Kidney Disease: Challenges, Progress, and Possibilities. CJASN. December 2017, 12 (12) 2032-2045

6. Bermejo S, Pascual J, Soler MJ. The current role of renal biopsy in diabetic patients. Minerva Med. 2018;109(2):116-125

7. Bermejo S, González E, López-Revuelta K, et al. Risk factors for non-diabetic renal disease in diabetic patients. Clin Kidney J. 2020;13(3):380-388. 
8. Olivarius Nde F, Andreasen AH, Keiding N, Mogensen CE. Epidemiology of renal involvement in newlydiagnosed middle-aged and elderly diabetic patients. Cross-sectional data from the population-based study "Diabetes Care in General Practice", Denmark. Diabetologia. 1993;36(10):1007-1016.

9. Levey AS, Stevens LA, Schmid CH, et al. A new equation to estimate glomerular filtration rate [published correction appears in Ann Intern Med. 2011 Sep 20;155(6):408]. Ann Intern Med. 2009;150(9):604-612

10. White SL, Chadban SJ, Jan S, Chapman JR, Cass A. How can we achieve global equity in provision of renal replacement therapy? Bull World Health Organ. 2008;86(3):229-237.

11. Serrano R, García-Soidán FJ, Díaz-Redondo A, et al. Cohort Study in Primary Health Care on the Evolution of Patients with Prediabetes (PREDAPS): basis and methodology. Rev Esp Salud Publica. 2013;87(2):121-135

12. Giráldez-García C, Sangrós FJ, Díaz-Redondo A, et al. Cardiometabolic Risk Profiles in Patients With Impaired Fasting Glucose and/or Hemoglobin A1c 5.7\% to 6.4\%: Evidence for a Gradient According to Diagnostic Criteria: The PREDAPS Study. Medicine (Baltimore). 2015;94(44):e1935.

13. Effect of intensive therapy on the development and progression of diabetic nephropathy in the Diabetes Control and Complications Trial. The Diabetes Control and Complications (DCCT) Research Group. Kidney Int. 1995;47(6):1703-1720

14. Global Recommendations on Physical Activity for Health.[cited Oct 20]. Available from:https://www.who.int/dietphysicalactivity/global-PA-recs-2010.pdf

15. Panagiotakos DB, Pitsavos C, Stefanadis C. Dietary patterns: a Mediterranean diet score and its relation to clinical and biological markers of cardiovascular disease risk. Nutr Metab Cardiovasc Dis. 2006;16(8):559-568

16. Landray MJ, Emberson JR, Blackwell L, et al. Prediction of ESRD and death among people with CKD: the Chronic Renal Impairment in Birmingham (CRIB) prospective cohort study. Am J Kidney Dis. 2010;56(6):1082-1094.

17. Di Micco L, Di Lullo L, Bellasi A, Di lorio BR. Very Low Protein Diet for Patients with Chronic Kidney Disease: Recent Insights. J Clin Med. 2019;8(5):718

18. Dunkler $D$, Dehghan $M$, Teo KK, et al. Diet and kidney disease in high-risk individuals with type 2 diabetes mellitus. JAMA Intern Med. 2013;173(18):1682-1692

19. Okada R, Yasuda Y, Tsushita K, Wakai K, Hamajima N, Matsuo S. Glomerular hyperfiltration in prediabetes and prehypertension. Nephrol Dial Transplant. 2012;27(5):1821-1825.

20. Pruijm M, Wuerzner G, Maillard M, et al. Glomerular hyperfiltration and increased proximal sodium reabsorption in subjects with type 2 diabetes or impaired fasting glucose in a population of the African region. Nephrol Dial Transplant. 2010;25(7):2225-2231

21. Neuringer JR, Brenner BM. Glomerular hypertension: cause and consequence of renal injury. $J$ Hypertens Suppl. 1992;10(7):S91-S97

22. Tonna S, El-Osta A, Cooper ME, Tikellis C. Metabolic memory and diabetic nephropathy: potential role for epigenetic mechanisms. Nat Rev Nephrol. 2010;6(6):332-341. 
23. Bilous R. Microvascular disease: what does the UKPDS tell us about diabetic nephropathy?. Diabet Med. 2008;25 Suppl 2:25-29.

24. Cortés-Sanabria L, Cabrera-Pivaral CE, Cueto-Manzano AM, et al. Improving care of patients with diabetes and CKD: a pilot study for a cluster-randomized trial. Am J Kidney Dis. 2008;51(5):777-788 .

25. Kopple JD. History of dietary protein therapy for the treatment of chronic renal disease from the mid 1800s until the 1950s. Am J Nephrol. 2002;22(2-3):278-283.

26. Chagnac A, Weinstein T, Herman M, Hirsh J, Gafter U, Ori Y. The effects of weight loss on renal function in patients with severe obesity. J Am Soc Nephrol. 2003;14(6):1480-1486.

\section{Tables}

Table 1. Demographic and clinical characteristics of participants at baseline. 


\begin{tabular}{|c|c|c|c|}
\hline \multirow[t]{2}{*}{ Characteristics } & Prediabetes & Normoglucose & \multirow[t]{2}{*}{$\mathrm{p}$ value } \\
\hline & $(n=1,072)$ & $(n=772)$ & \\
\hline Age (years), mean (SD) & $59.1(9.3)$ & $56.6(10.3)$ & $<0.001$ \\
\hline Male, n (\%) & $536(50.0)$ & $358(46.4)$ & 0.068 \\
\hline \multicolumn{4}{|l|}{ Smoking status, $\mathrm{n}(\%)$} \\
\hline Active smoker & $182(17.0)$ & $170(22.0)$ & \multirow[t]{3}{*}{0.003} \\
\hline Ex-smoker & $409(38.2)$ & $244(31.6)$ & \\
\hline Never smoker & $481(44.9)$ & $358(46.4)$ & \\
\hline Regular physical activity, n(\%) & $575(53.7)$ & $428(55.4)$ & 0.249 \\
\hline High-risk alcohol consumption, $\mathrm{n}(\%)$ & $140(13.1)$ & $83(10.8)$ & 0.078 \\
\hline Adherence Mediterranean diet score, $\mathrm{n}(\%)$ & $564(52.6)$ & $370(47.9)$ & 0.026 \\
\hline Daily consumption of fruit or vegetables, $n(\%)$ & $919(85.7)$ & $653(84.6)$ & 0.269 \\
\hline Metabolic syndrome, $n(\%)$ & $559(52.1)$ & $96(12.4)$ & $<0.001$ \\
\hline Waist circumference (cm), mean (SD) & $100.1(12.3)$ & $93.0(11.8)$ & $<0.001$ \\
\hline BMI $\left(\mathrm{kg} / \mathrm{m}^{2}\right)$, mean $(\mathrm{SD})$ & $29.9(4.8)$ & $27.4(4.4)$ & $<0.001$ \\
\hline Fasting plasma glucose $(\mathrm{mg} / \mathrm{dL})$, mean (SD) & $105.2(10.9)$ & $87.0(7.2)$ & $<0.001$ \\
\hline HbA1c (\%), mean (SD) & $5.8(0.3)$ & $5.3(0.3)$ & $<0.001$ \\
\hline \multicolumn{4}{|l|}{ Hemoglobin (g/dL), n(\%) } \\
\hline$\geq 13.0$ & $975(91.0)$ & $665(86.1)$ & \multirow[t]{3}{*}{0.005} \\
\hline $12.9-11.0$ & $91(8.5)$ & $102(13.2)$ & \\
\hline$\leq 10.9$ & $6(0.6)$ & $5(0.6)$ & \\
\hline Hypertension, n(\%) & $708(66.0)$ & $359(46.5)$ & $<0.001$ \\
\hline SBP (mmHg), mean (SD) & $134.6(16.0)$ & $128.3(15.3)$ & $<0.001$ \\
\hline $\mathrm{DBP}(\mathrm{mmHg})$, mean (SD) & $81.2(9.4)$ & $79.0(9.5)$ & $<0.001$ \\
\hline Total colesterol (mg/dL), mean (SD) & $209.9(37.4)$ & $211.0(37.5)$ & 0.532 \\
\hline HDL-cholesterol (mg/dL), mean (SD) & $54.4(14.3)$ & $58.5(15.6)$ & $<0.001$ \\
\hline
\end{tabular}




\begin{tabular}{|llll|}
\hline Non HDL-cholesterol (mg/dL), mean (SD) & $129.6(33.9)$ & $129.8(32.2)$ & 0.899 \\
\hline Triglycerides (mg/dL), mean (SD) & $132.3(71.7)$ & $114.4(75.6)$ & $<0.001$ \\
\hline Use of ACEls or ARBs, $\mathrm{n}(\%)$ & $396(36.9)$ & $182(23.6)$ & $<0.001$ \\
\hline Creatinine(mg/dL), mean (SD) & $0.8(0.2)$ & $0.8(0.2)$ & 0.760 \\
\hline eGFR (mL/min per 1.73 m²), mean (SD) $^{2}$ & $89.1(13.7)$ & $90.4(13.4)$ & 0.060 \\
\hline $\begin{array}{l}\text { SBP= systolic blood pressure; DBP= diastolic blood pressure; ACEls=angiotensin converting } \\
\text { enzyme inhibitors; ARBs=angiotensin receptor blockers; eGFR=estimated glomerular filtration rate. }\end{array}$ & \\
\hline
\end{tabular}

Table 2. Five-year rate of incidence of impaired renal function per 100 person-years by cohort and prediabetes type.

\begin{tabular}{|c|c|c|c|}
\hline & $\begin{array}{l}N^{0} \text { of } \\
\text { cases }\end{array}$ & $\begin{array}{l}\text { Person- } \\
\text { years }\end{array}$ & $\begin{array}{l}\text { Rate of incidence (100 person- } \\
\text { years) }\end{array}$ \\
\hline \multicolumn{4}{|l|}{ COHORT } \\
\hline Prediabetes & 88 & 4,928 & 1.79 (95\%Cl: 1.45-2.20) \\
\hline Normoglycemia & 61 & 3,555 & 1.72 (95\%Cl: 1.34-2.21) \\
\hline \multicolumn{4}{|l|}{ PREDIABETES TYPE } \\
\hline HbA1c 5.7- $6.4 \%$ & 19 & 1,359 & 1.40 (95\%Cl: 0.89-2.19) \\
\hline FPG $100-125$ mg/dL & 22 & 1,066 & $2.06(95 \% \mathrm{Cl}: 1.36-3.13)$ \\
\hline $\begin{array}{l}\mathrm{HbA} 1 \mathrm{c} 5.7-6.4 \% \text { \& FPG 100-125 } \\
\mathrm{mg} / \mathrm{dL}\end{array}$ & 47 & 2,503 & 1.88(95\%Cl: 1.41-2.50) \\
\hline
\end{tabular}

Table 3. Association risk of comorbidities and lifestyle factors with risk of IRF development. 


\begin{tabular}{|c|c|c|}
\hline & $\mathrm{HR}$ & $95 \% \mathrm{Cl}$ \\
\hline \multicolumn{3}{|l|}{ Age } \\
\hline 30 to 49 years & 1.00 & \\
\hline 50 to 64 years & 5.12 & $(1.85-14.15)$ \\
\hline 65 to 74 years & 16.43 & $(6.04-44.73)$ \\
\hline Sex (male) & 1.09 & $(0.79-1.50)$ \\
\hline \multicolumn{3}{|l|}{ Smoking status } \\
\hline Active smoker & 1. 00 & \\
\hline Ex-smoker & 0.93 & $(0.57-1.53)$ \\
\hline Never smoker & 0.78 & $(0.47-1.28)$ \\
\hline Regular physical activity (no) & 0.97 & $(0.70-1.35)$ \\
\hline High-risk alcohol consumption (no) & 1.28 & $(0.74-2.20)$ \\
\hline Adherence Mediterranean diet score (no) & 0.75 & $(0.54-1.04)$ \\
\hline Daily consumption of fruit or vegetables (no) & 1.18 & $(0.66-2.10)$ \\
\hline Metabolic syndrome (no) & 1.14 & $(0.82-1.59)$ \\
\hline Waist circumference $(\mathrm{cm})$ & 1.39 & $(0.98-1.98)-$ \\
\hline $\mathrm{BMI} \geq 30\left(\mathrm{~kg} / \mathrm{m}^{2}\right)$ & 1.21 & $(0.87-1.68)$ \\
\hline Hypertension, (no) & 2.08 & $(1.38-3.12)$ \\
\hline Total cholesterol $\geq 250 \mathrm{mg} / \mathrm{dL}^{*}$ & 1.15 & $(0.74-1.81)$ \\
\hline Low HDL-cholesterol mg/dL* & 1.28 & $(0.86-1.91)$ \\
\hline Triglycerides $\geq 200 \mathrm{mg} / \mathrm{dL}$ & 1.00 & $(0.68-1.45)$ \\
\hline Use of ACEls or ARBs (no) & 1.82 & $(1.31-2.52)$ \\
\hline
\end{tabular}

Model 1 (sex- and age-adjusted)

* $\mathrm{HDL}-\mathrm{C}$ of $<40 \mathrm{mg} / \mathrm{dL}$ in $\mathrm{men}$ or $<50 \mathrm{mg} / \mathrm{dL}$ in women

Table 4-Hazard ratio of IRF associated to prediabetes and type of prediabetes using different models 


\begin{tabular}{|lllllllll|}
\hline & \multicolumn{2}{l}{ Model 1 } & \multicolumn{2}{l}{ Model 2 } & \multicolumn{2}{l|}{ Model 3 } & \multicolumn{2}{l|}{ Model 4 } \\
\hline & HR & $95 \% \mathrm{Cl}$ & HR & $95 \% \mathrm{Cl}$ & HR & $95 \% \mathrm{Cl}$ & HR & $95 \% \mathrm{Cl}$ \\
\hline Normoglycemia & ref & & & & & & & \\
\hline Prediabetes & 0.89 & $(0.64-$ & 0.90 & $(0.65-$ & 0.76 & $(0.54-$ & 0.76 & $(0.54-$ \\
& & $1.24)$ & & $1.25)$ & & $1.07)$ & & $1.07)$ \\
\hline HbA1c 5.7- 6.4 \% & 0.71 & $(0.43$ & 0.72 & $(0.43$ & 0.68 & $(0.40$ & 0.68 & $(0.40$ \\
& & $-1.20)$ & & $-1.21)$ & & $-1.14)$ & & $-1.15)$ \\
\hline FPG 100-125 mg/dL & 1.24 & $(0.76$ & 1.28 & $(0.78$ & 1.10 & $(0.66$ & 1.12 & $(0.68$ \\
& & $-2.03)$ & & $-2.11)$ & & $-1.82)$ & & $-1.85)$ \\
\hline HbA1c: $5.7-6.4 \%$ \& FPG & 0.87 & $(0.59$ & 0.87 & $(0.59$ & 0.69 & $(0.46$ & 0.68 & $(0.45$ \\
100-125 mg/dL & & $-1.27)$ & & $-1.28)$ & & $-1.03)$ & & $-1.02)$ \\
\hline
\end{tabular}

Model 1 (sex- and age-adjusted)

Model 2 (Model 1 plus adjusted by lifestyle variables (i.e. smoking status, regular physical activity, highrisk alcohol consumption, adherence Mediterranean diet (MedDiet) score, and daily consumption of fruit or vegetables)

Model 3 (Model 2 plus adjusted by metabolic risk factors (i.e. Waist circumference, BMI, hypertension, total cholesterol, HDL-cholesterol, triglycerides s)

Model 4 (Model 3 plus adjusted by use of ACEls or ARBs)

\section{Figures}




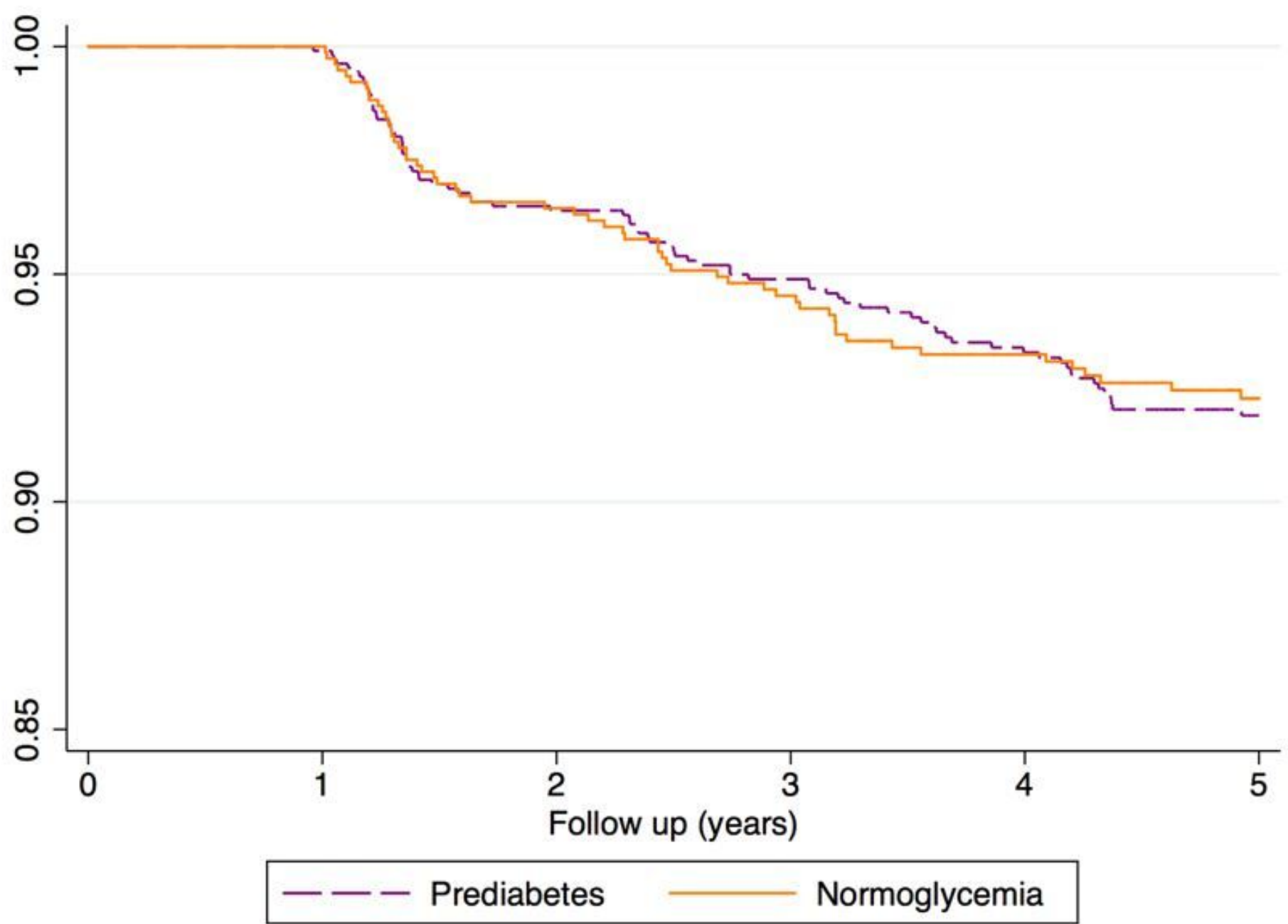

Figure 1

Kaplan-Meier survival estimate showing time to IRF onset according to prediabetes status 


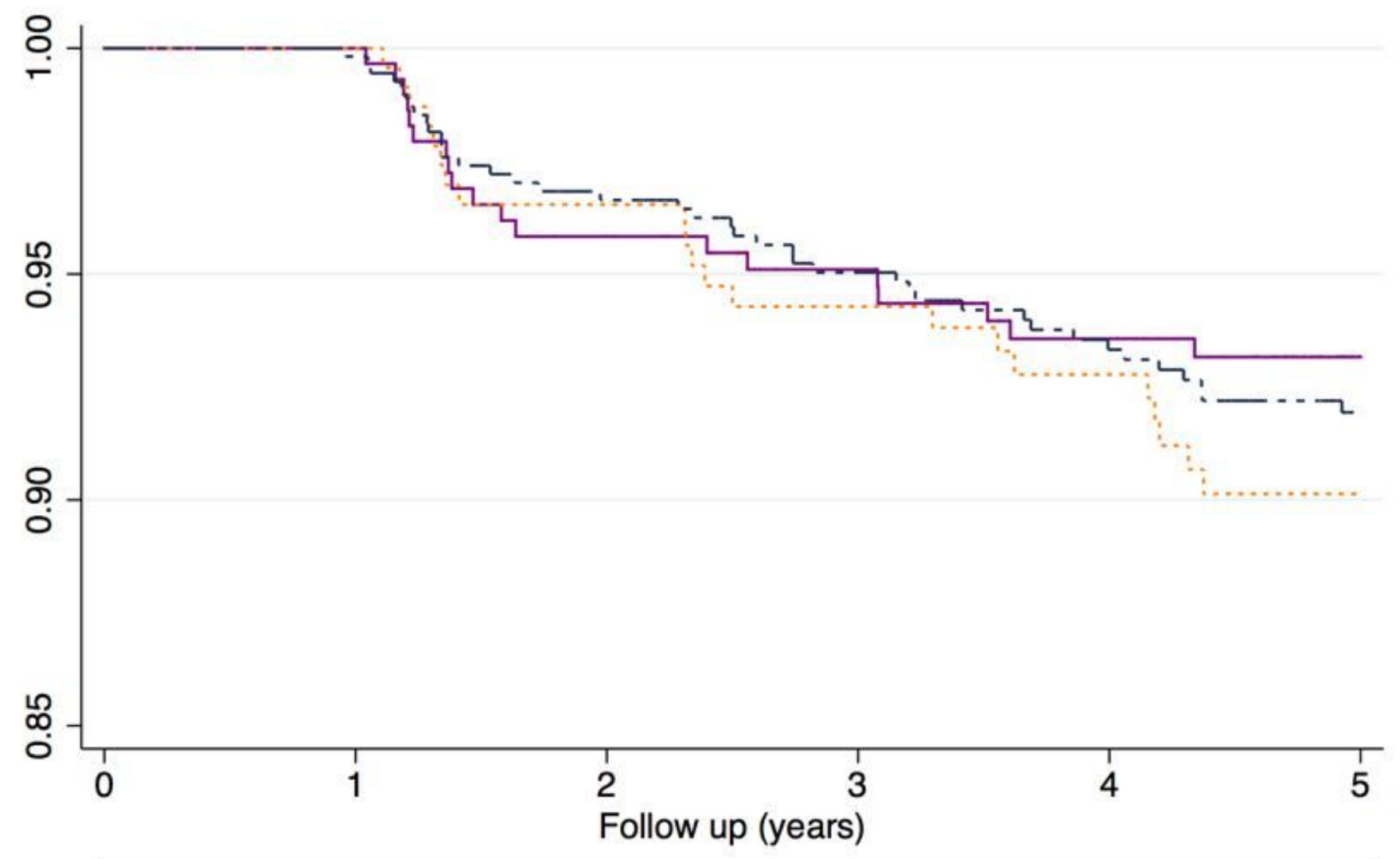

$\mathrm{HbA1c} 5.7-6.4 \%$

FPG $100-125 \mathrm{mg} / \mathrm{dL}$

Figure 2

Kaplan-Meier survival estimate showing time to IRF onset according to type of prediabetes 